\title{
DESIGNING EMOTIONAL AWARENESS DEVICES: WHAT ONE SEES IS WHAT ONE FEELS
}

\section{DISEÑANDO DISPOSITIVOS CON AWARENESS EMOCIONAL: LO QUE UNO VE ES LO QUE UNO SIENTE}

\author{
Andrés Neyem $^{1} \quad$ Cristian Aracena $^{2} \quad$ César A. Collazos $^{3} \quad$ Rosa Alarcón $^{4}$
}

Recibido 8 de enero de 2007, aceptado 23 de agosto de 2007

Received: January 8, 2007 Accepted: August 23, 2007

\begin{abstract}
RESUMEN
La comunicación interpersonal requiere más que solamente palabras, involucra emociones. En términos generales las emociones pueden ser vistas como estados internos complejamente organizados. El Awareness de estos estados permitiría a los seres humanos evaluar la información social y desarrollar inteligencia social estratégica y, por lo tanto, las acciones cotidianas estarían teñidas de significado social y emocional. Este artículo reporta una experiencia que busca permitir un diálogo basado en emociones expresadas, capturadas y transmitidas entre diversos participantes usando interfaces tangibles. Además, se explota el significado social de objetos físicos y cotidianos como un portarretratos, con el fin de crear interfaces afectivas entre usuarios dispersos geográficamente. En este artículo se describe un dispositivo que permite un tipo de Awareness emocional apoyando la interacción interpersonal y afectiva entre personas distantes geográficamente.
\end{abstract}

Palabras clave: Awareness emocional, computación pervasiva, interfaces de usuario tangibles, interfaces afectivas.

\section{ABSTRACT}

Interpersonal communication involves more than just words; it involves emotion. Emotions can be roughly seen as complex organized internal states. Awareness of those states would allow human beings to evaluate social information and develop strategic social intelligence and hence, everyday actions convey social meaning and emotion. This paper reports an experience for supporting public-emotion based dialogs, where emotions are expressed, captured and transmitted between distant participants using tangible interfaces. We also exploit the social meaning of an everyday physical object such as a portrait, in order to create affective interfaces. We describe as well, a device that allows Emotional Awareness and supports the affective interpersonal interaction among people across distance.

Keywords: Emotional awareness, pervasive computing, tangible user interfaces, affective interfaces.

\section{INTRODUCTION}

Although there is not a complete understanding regarding its nature, some researchers have described emotions as complex organized states consisting of cognitive appraisals, action impulses, and patterned somatic reactions [17]. Others describe them as physiological states of the human body. The awareness of those body states or emotions (sometimes called feelings) would allow human beings to evaluate social information through analogies and become the basis of communication [5].
Emotions play an important role in human interaction and are a central aspect in all levels of human behavior: sociological, psychological, and physiological. Emotions are a social need and represent an important channel of communication with one-self and others, playing an important role in social interaction and rational thinking [6]. Our emotions are a valuable information source that helps us to make decisions. Some studies show that when a person's emotional connections are detached in the brain, s/he cannot make even the simplest decisions [6]. Emotions allow us to transmit and infer extra information

Departamento de Ciencias de la Computación. Universidad de Chile. Av. Blanco Encalada 2120. Santiago, Chile. E-mail: aneyem@dcc.uchile.cl

Departamento de Ciencias de la Computación. Universidad de Chile. Av. Blanco Encalada 2120. Santiago, Chile. E-mail: caracena@dcc.uchile.cl

Departamento de Sistemas, FIET. Grupo IDIS. Universidad del Cauca. Sector Tulcán. Popayán, Colombia. E-mail: ccollazo@unicauca.edu.co

4 Departamento de Ciencias de la Computación. Pontificia Universidad Católica de Chile. Av. Vicuña Mackenna 4860, 6904411. Santiago, Chile. E-mail: ralarcon@ing.puc.cl 
when we are communicating with others. Our facial expressions, for example, can convey a wide range of emotions: if we look sad or hurt, we are signaling to others that we need their help. If we are verbally skilled we will be able to express appropriately our emotional needs and thereby we could have the chance of fulfilling them. If we are effective at listening to the emotional needs of others, we could help them feeling understood, important and cared. On the other hand, less socially skilled people find difficult to express their emotions verbally or to interpret the environment and make an appropriate emotional response.

Emotion expression can be facilitated, especially through non-verbal methods. There are many activities that encourage non-verbal emotional expression [18]. For example: Caring for plants or pets express feelings of caring, affection, satisfaction, and responsiveness for living things; Listening to our favourite music or singing recalls the feelings associated with the music; Performing a repetitive physical activity such as walking, digging the garden, or shredding papers for recycling, provide a release for feelings of frustration; Holding hands, hugging, brushing hair, rubbing on hand cream or other adult uses of touch are acceptable, adult expressions of caring and concern; Simple household chores, such as dusting, drying dishes, or preparing vegetables enhances feelings of usefulness and self-worth.

Emotional cues can be found as well in the individual's home or workplaces, where physical items and their arrangement provide contextual information for others and serve as a means of expression among people (i.e. adorns on the walls; chocolates on the coffee table; portraits, toys, art and other personal items on the desks, etc.). This personalization may add elements of comfort to people's physical space, and also it can be a form of communication and expression of their individuality for those who share that person's space even for a short time. Visitors can view and discuss photographs or manipulate physical artifacts, such as awards or toys, thereby expressing interest in the owner's personality and learning his or her preferences and situation. The subtle, non verbal cues and the contextual cues (such as chocolates from a trip or a funny comic from the newspaper), serve as a basis to disambiguate emotion understanding and expression. However, this type of casual but personal communication can be very difficult at a distance, because of the impossibility of physical access to other's personal space and artifacts.

For more complex environments (e.g. human-to-human interaction) it is important not only to understand other's emotions appropriately but also to acknowledge such understanding, letting people know that we are aware of their feelings. Emotion-based interaction may occur at low level by reading non-verbal cues (e.g. facial expression, the tone of the voice, etc.) or at a higher level of abstraction through dialogues (e.g. "You seem to be very upset. Is that true?", "Are you upset because...?" in order to acknowledge and disambiguate the perceived feeling).

Emotional awareness had captured the attention of the Computer Supported Collaborative Work area recently [10]. It can be used to provide feedback to students and instructors in distance learning environments and to support group decision in Electronic Meeting Rooms. Emotional awareness can be used to provide contextual information for a better understanding of the information retrieved from an organizational memory system, or as an input to collaborative filtering systems. In the latter case, the concern is not on recognizing and responding automatically to human emotions, but in to allow group members to become aware of others' emotions, so that communication bandwidth is enriched.

Which one is the best approach for representing emotion trough a user interface is an open issue [10]. Another strong concern is individuals' feelings privacy, mostly in collaborative environments were individuals are used to discuss and negotiate complex subjects, and the accurate recognition of others' feeling may be seen as an unfair advantage but also as a social need for an effective negotiation.

In order to get an insight into these conflicting needs, we have developed a mechanism for allowing users to explicitly express their feelings and communicate them at a distance. Such communication is received by a remote device that physically changes, modifying this way the remote physical space. The remote partner will receive information regarding his or her partner's personal situation, actions, thoughts and emotions. This paper explores affective communication based on Tangible User Interfaces (TUIs), using Phidgets [11], and placing a strong emphasis on touch and physicality as well as on exploiting the meaning and cultural usage associated with everyday physical objects. We propose and discuss some design guidelines and issues in this area.

Our approach is to build shared digital spaces where emotional interaction occurs and is expressed (a WYSIWIF, What You See Is What I Feel approach). In order to accomplish this goal, we have exploited the semantics associated to an object such as a portrait (e.g. that it allows to recall emotions associated to particular circumstances). We have enriched the everyday portrait so that it can indicate/represent some human emotions enabling an affective communication. 


\section{RELATED WORK}

The Emotional Intelligence Group [7] has defined the next levels of emotional awareness as: knowing when feelings are present in ourselves and others, knowing the feeling is present, acknowledging the feeling, identifying the feeling, accepting the feeling, reflecting on the feeling, and forecasting feelings.

Emotional Awareness uses different mechanisms to communicate emotional states, such as GUI widgets, however, the emphasis on GUIs interfaces has become to change so as to include physical user interfaces augmented by computing power [11]. Those interfaces are widely studied in areas such as ubiquitous computing, calm technology [26], pervasive computing [1], and tangible user interfaces, among others.

Many researchers work on diverse methods for delivering specific information into the physical environment in a non-intrusive manner, using ambient/peripheral output $[12$, 19]. We are not concerned with conveying information, but conveying feelings and triggering emotional responses in the recipient.

We want also to do so in a physical and semi-persistent environment. Related research such as LumiTouch [4], Peek-A-Drawer [23], and TSUNAGARI [14] explore the use of ambient display as a means for supporting interpersonal communication. However, these projects limit the interaction and a person can receive a poor token of affection [16] from virtually anyone they meet. An important issue when designing environments that provide Emotional Awareness is the need that physical artifacts must support and communicate several tokens of affection in a semitransparent way.

Our approach is to allow users to interact with each another by sending and receiving directed tokens of affection, from very well know people transparently. Transparence is related to allowing users to focus on the task at hand instead of on the technology. In our approach we provide transparency by enriching personal artifacts whose social meaning is related to emotion expression such as a portrait with computational power. Photographs of "loved beings" or "unforgettable moments" are symbols of a personal bond and provide a constant reminder of the feelings and emotions associated to that particular time frame or circumstances. Photographs are an important part of many people's life; they arrange their personal pictures on their desks and around their homes.
Commercial products, such as the Ceiva system [3] are becoming popular for displaying personal digital photos, but lack the possibility of affective communication. Ceiva provides an LCD display in an attractive frame that cycles through pictures uploaded and configured through a Web service. The Web service allows users configuring a set of photos for display as well as determining the set provider. As our focus is on facilitating emotional content communicating and enabling presence detection, we developed a physical device called "Emoti-Picture Frame". This device was designed to be an asymmetric, bi-directional channel of communication over Internet. The approach is similar to the model proposed by Hiroshi Ishii, in his research about interpersonal communication [4]. There, he discusses user interaction and highlights the use of light as both, an ambient representation and an active data transmission medium, allowing designers to switch the user's focus of attention between passive and active modes. In our case, the use of light in conjunction with picture represents an emotional state. Our device could be situated in the relatively unexplored region between ambient and direct communication (figure 1).

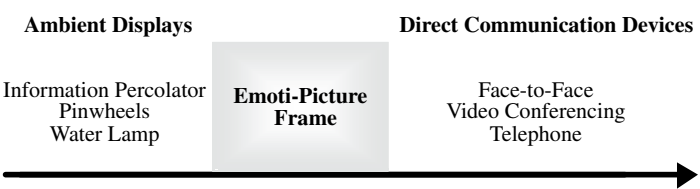

Figure 1. Attention requirement spectrum.

Our design allows emotionally related people such as family members, couples or friends, that are living or working geographically distanced, to gaze often at a picture of their "loved beings" wondering, "Are they thinking of me? If I could share my feelings.". The Emoti-Picture Frame explores the design of a communication medium to convey emotional features.

\section{PHYSICAL USER INTERFACES}

For many years our conception of Human-Computer Interaction (HCI) has been focused on GUIs [13]. GUIs allow interaction with digital objects and online information through the generic screen, keyboard, and pointing device, among others. However, in the everyday situation, touching and physical manipulation play a key role in understanding our environment [13]. Traditional interfaces, in contrast, largely fail to address our need of touching, manipulating and arranging physical objects and offer only a keyboard 
and a pointing device as tools for direct manipulation of digital objects $[11,13]$.

Physical User Interfaces represent a general approach to HCI. Some years ago, Hiroshi Ishii introduced the concept of Tangible User Interfaces (TUI) [13]. Those interfaces put greater emphasis on physicality than traditional graphics-based interfaces. Later, Greenberg introduced the concept of Physical widgets or Phidgets [11]. Phidgets are to physical user interfaces what widgets are to graphical user interfaces.

Similar to widgets, phidgets are interface elements that allow abstracting and packaging some input (or output) mode of interaction. They hide implementation and construction details, expose functionality through a welldefined API, and have an (optional) on-screen interactive interface for displaying and controlling its state. Unlike widgets, phidgets also require:

- A connection manager that tracks how devices appear on-line; that is, a way to link a software phidget with its physical counterpart.

- A simulation mode that allows programmers to develop, debug and test a physical interface even when no physical device is present.

The next section presents the Physical Interface and the GUI developed.

\section{IMPLEMENTATION}

Our current prototype explores the concept of spaces for affective communication, opened to anyone who wants to participate in it. We have focused on a Web-based system that communicates feelings through physical devices in the user's personal space. Because distance typically makes it difficult for those who communicate to view the outcome of their actions, each design focuses on the ability to give feedback about action's results, but at an emotional level. We are exploring open participation, with additional feedback to the users. We want to make it even easier, and instantaneous, for remote friends and family, to share and direct their attention to a photo. Emotional awareness is triggered on remote people when they perceive the changes of the current photo on a picture frame representing the emotional states of the person portrayed.

\section{Prototype}

The Emoti-Picture Frame allows anyone with Internet access to transmit their feelings as a way of communicating emotions and display them on a TUI (figure 2), a GUI (figure 5) interface or both.

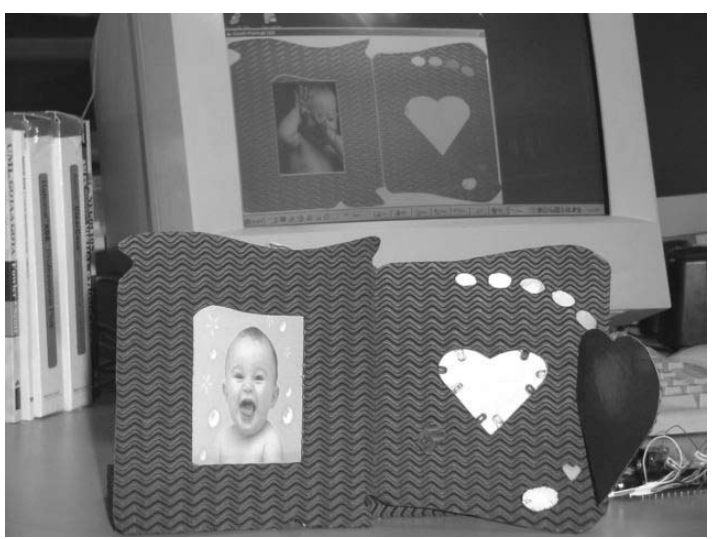

Figure 2. TUI and GUI versions of Emoti-Picture Frame.

The TUI version is designed as component Phidgets [11] and the GUI, developed in C\#, is composed from the information generated by the Phidgets through APIs provided by the respective supplier [19]. The TUI considers the following elements of Phidget starter kit \#1: a PhidgetInterfaceKit 8/8/8, 2 touch sensors, 4 red and 4 green LEDs, 6 pushbuttons, 1 servomotor, and 2 USB cable.

The design of TUI is summarized in the plane of the figure 3 and its implementation is presented in figures 2, 4 and 5 .

Conceptually, the Emoti-Picture Frame has been designed to be used like an everyday picture frame. It is composed by two main parts (figure 5):

- A picture area, which shows a picture that, represents an emotional state of a remote person.

- A feeling area, which is composed by Emotional Buttons, a Heart shaped-Emotional Indicator and History-Emotional Buttons.

When the user wants to transmit some feeling, he or she has to press any Emotional Button. Each color-buttons represent some emotional state (figure 6):

- White color represents a neutral emotional state.

- Yellow color represents a happy emotional state.

- Blue color represents a melancholic emotional state.

- Gray color represents a sad emotional state.

- Red color represents an angry emotional state. 


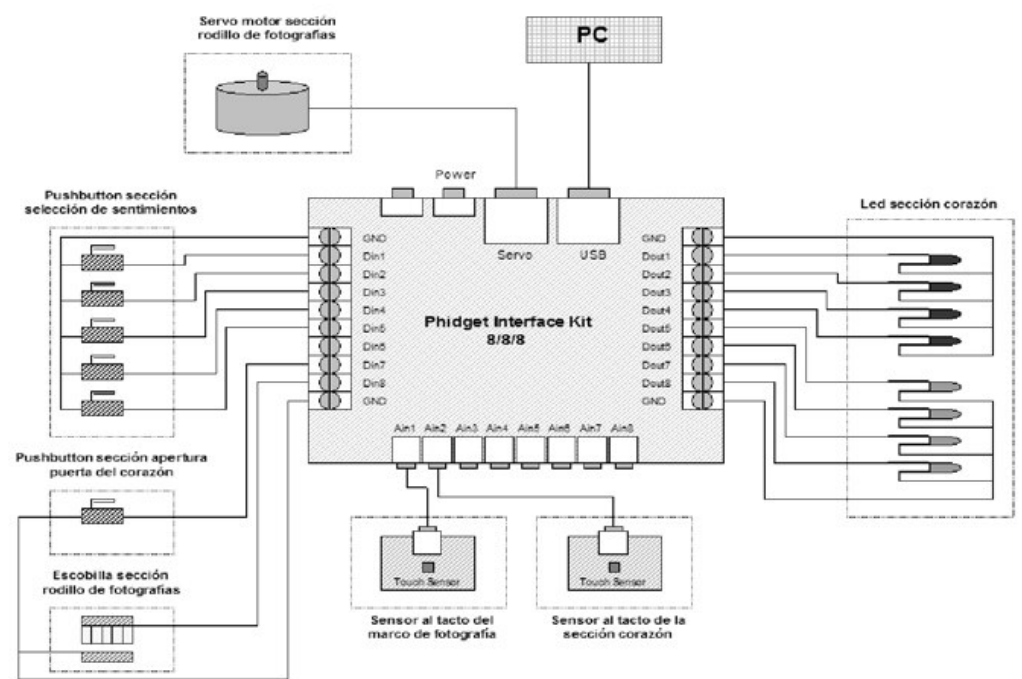

Figure 3. Electrical design of the TUI.

The emotions that a user can communicate are showed in table 1. These colors are intended to provide information about the emotional state to transmit. There are many researchers that have investigated how to represent emotional characteristics using colors $[20,22,24,25]$.

Table 1. Emotions that users can communicate.

\begin{tabular}{|c|c|c|c|c|}
\hline \multicolumn{3}{|c|}{ Emotion } & $\begin{array}{c}\text { Emotional } \\
\text { Buttons } \\
\text { Pressed }\end{array}$ & $\begin{array}{l}\text { Touch } \\
\text { the } \\
\text { picture }\end{array}$ \\
\hline \multicolumn{3}{|c|}{ I am thinking about you } & None & Yes \\
\hline \multicolumn{3}{|c|}{ I am neuter } & white color & No \\
\hline \multicolumn{3}{|c|}{ I am happy } & yellow color & No \\
\hline \multicolumn{3}{|c|}{ I am melancholic } & blue color & No \\
\hline \multicolumn{3}{|c|}{ I am sad } & gray color & No \\
\hline \multicolumn{3}{|c|}{ I am angry } & red color & No \\
\hline \multicolumn{3}{|c|}{ I am neuter with you } & white color & Yes \\
\hline \multirow[t]{3}{*}{ I am } & happy & \multirow{3}{*}{$\begin{array}{l}\text { Because } \\
\text { I am } \\
\text { thinking } \\
\text { about }\end{array}$} & yellow color & Yes \\
\hline & melancholic & & blue color & Yes \\
\hline & Sad & & gray color & Yes \\
\hline \multicolumn{3}{|c|}{ I am angry with you } & red color & Yes \\
\hline
\end{tabular}

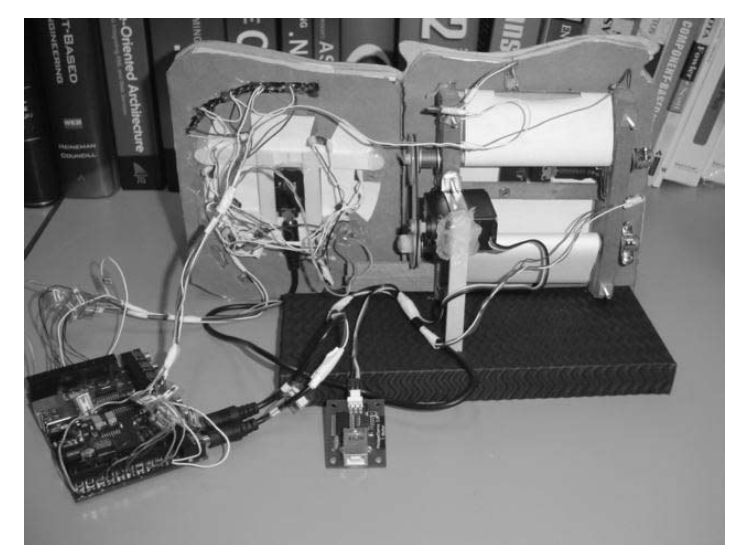

Figure 4. Rear view of the Emoti-Picture Frame.

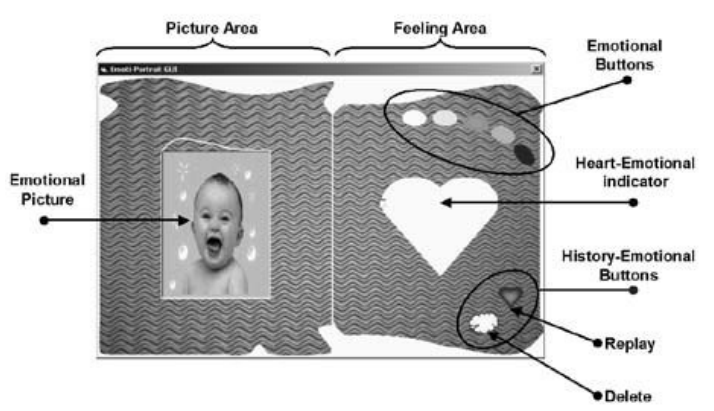

Figure 5. Parts of Emoti-Picture Frame. 


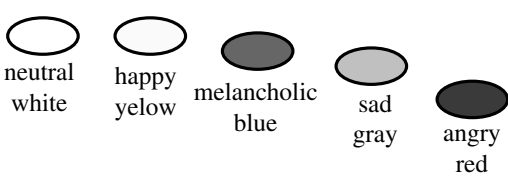

Figure 6. Color associated to emotions.

Each emotion state received is stored in a history database for later replay when the user presses one of the HistoryEmotional Buttons (represented as a red heart in figure 5). If the user wants to erase the history, $\mathrm{s} /$ he has to press the button using the delete icon (depicted as a white ellipse in figure 5).

When any emotional state is arriving to the EmotiPicture Frame, it will shows a picture associated with the emotional state received and the red LEDs located around the Heart-Emotional Indicator will blink, signaling the arrival of an emotion. If a user wants to communicate the emotion "I'm thinking about you", s/he must touch the picture located in the Emotional Picture zone. Then, the Emoti-Picture Frame will show a picture with green LEDs blinking signaling that an emotion has arrived. The user can stop the blinking of the Heart-Emotional Indicator, simply by touching the surface of the heart.

Additionally the user can block the reception of emotions by closing the portal of the Heart-Emotional Indicator, this action is never informed to the other user and all the emotional states that are received after such action are stored in the history database for a later optional recovery.

\section{Communication}

The Emoti-Picture Frame allows two kind of communication, Passive or Active Communication.

\section{Passive Communication}

When a remote user is in front of Emoti-Picture Frame, the local Emoti-Picture Frame will emit an ambient glow indicating her/his remote presence and emotional state. When the light is green and blinking, it indicates the emotion "I am thinking about you". When the light is red and blinking, it indicates the emotion associated to the picture portrayed (the Emotional Picture of figure 5). That is, it could be neutral, happy, melancholic, sad or angry. This additional background information helps people to figure out whether there is a recipient on the other side or not, and guess if there is a convenient time for increasing the interaction level (e.g. by starting an active communication mode or by using an alternative, like a phone).

\section{Active Communication}

Occurs when a user picks up the picture frame and transmits some emotion as a response to a previous interaction. Although in this prototype this kind of Communication is very reduced, it could be easily increased, for example, by adding different LEDs' colors around the Heart-Emotional Indicator, similarly to Lumitouch [4].

The system was intended to allow users to develop an abstract form of emotional language (a particular interpersonal language). People can communicate, in real-time, by sending each other colored messages associated to emotional states (e.g. green and red color associated to a sad picture will communicate an emotion such as "I am sad because I am thinking about you"). The combination of colors and emotional state allow a limited grammar and syntax for creative interpersonal dialect between two people (e.g. green and red color with the angry picture communicate that the emotion of person is "I am angry with you").

Next section presents and discusses some design guidelines and issues we have explored in the creation of this application.

\section{CASE STUDY AND LESSONS LEARNED}

In addition to the prototype described here, we are experimenting with different media and devices for remote affective communication. Testing was done with users who were emotionally involved with each other (e.g. mother and son).

With the help of under-graduate students at our university, the Emotive-Picture Frame, in its TUI and GUI versions, has been tested in three cases involving different types of relations with a testing time ranged from 2 to 3 days.

- Case 1: Mother (GUI) and son (GUI and TUI).

- Case 2: Brother (GUI and TUI) and sister (GUI).

- Case 3: Boyfriends (GUI and TUI).

The first two cases involved people living in distant cities, which do not visit one another frequently. The Emotive-Picture Frame was used at their workplace during working time. From the experience, we highlight the following issues, which were presented indistinctly in all the three cases.

- At the beginning, the Emotive-Picture Frame was perceived as a disrupting element for the activities 
in the workplace, since a lot of attention was given to the emotional interaction. Later on, the EmotivePicture Frame was assimilated and incorporated in a transparent way to the workplace. For future work, we want to improve Emotive-Picture Frame GUI in order to make it less intrusive. For instance, instead of a window-based application, we want to embed notifications in the Windows' taskbar. We want as well, to replace the TUI interface by a touch screen, flattening the device so that it resembles more closely a regular portrait.

- In its first version, several problems were presented related to the configuration and synchronization of the remote connection. This is because we tested the device in a naturalistic environment and then circumstances such as heterogeneity interfered with the device set up. For instance, asynchronous messaging was not provided in order to avoid loss of interaction due to the unavailability of one of the users. A transparent way for configuring a remote connection was neither provided because it required the support of network administrators in the users' workplace: as the prototype used sockets, it required a fixed IP number for each workstation; firewalls could become a problem as well. We intend to improve this shortcoming in future versions.

- All the users reported that the system presented a useful and enjoyable way of transmitting emotions through a simple interface and the prototype allowed them to control which pictures were the appropriate for conveying a particular emotion.

- Finally, users reported that Emotive-Picture Frame contributed to increase other types of communication among them evidenced, as for example through a higher frequency of phone calls or e-mails interchange. This could be due to the strengthening of their bonds through the increase of affective communication. Such increment of communication lasted after the experiment ended up and slowly decayed afterwards. However, as reported by users, the increase in communication did not affect the normal flow of their working day.

An observer commented that he would like to give EmotiPicture Frame to a sibling who is currently in the hospital suggesting that people who are unable to communicate for long periods of time (e.g. sick or elderly) might be able to use the passive transmission of Emoti-Picture Frame in order to be aware of the feelings of their relatives. Another observer noted that a potential problem might arise from the asymmetry of participation. One person is engaged in an active interaction mode while the other passively perceives ambient data. The transmitting person may be anxious and expects that the receiver responds. However, if someone is so anxious so as to require immediate communication, s/he can just use the phone, or other higher-bandwidth alternative.

\section{DISCUSSION}

Emotions are a central aspect in all levels of human behavior: sociological, psychological, and physiological. Emotions are a social need and represent an important channel of communication with one-self and others, playing an important role in social interaction and rational thinking [5]. The study of emotions is not new, there has been numerous research works in areas such as neurology, psychology and physiology. Recently a new research area comprising this disciplines as well as computer science has emerged: Affective Computing or computing that relates to, arises from, or deliberately influences emotions [20].

Current communication tools do not allow us to easily express complex thoughts, affections and emotional state in a simple semi-anonymous way and feelings are interpreted by people in a subjective manner. The scenario gets worse when people are distanced, and many forms of interpersonal interaction become harder to achieve. We are exploring devices to enable this kind of remote interpersonal communication where feelings are expressed explicitely.

From a human interaction perspective, desktop computers are extremely limited machines with hardly any physicality to it. They engage only a fraction of the human sensory bandwidth. Physical interfaces can offer a direct relationship between information and control, and even allow direct control of virtual objects through physical objects. Laurel discusses how traditionally interaction technology interfaces are considered as intermediaries between the person and what they want to achieve [16]. Having good control is rated by people as one of the important aspects of a pleasurable product [9]. Schneiderman [21] suggests that people like to have control of their interactions as it gives them a sense of power over the system.

Physical interfaces could satisfy such needs. For instance, the previously presented device, allows users to express, perceive and communicate feelings which may help user's decision making and action. The proposed paradigm may be understood as WYSIWIF (What You See Is What I Feel). Nevertheless, the followed approach emphasizes user control and lets them decide what emotion they want to report to others. In this sense, they are publicly available 
to others while internal feelings may differ. This concept can be useful in other scenarios such as collaborative work, where the importance of using various communication channels, including the emotional one, in order to improve group members' interaction, is well known [10]. We would like to experience with another type of physical devices that could be adapted to a group work setting, allowing different emotions such as fear, acceptance, boredom, etc. to be displayed in a natural way, in order to lessen possible misunderstandings and cultural differences among group members. Naturally, there is a privacy concern when a group of team members are allowed to perceive emotions displayed in a shared physical environment (e.g. an office), however, please recall that these are public emotions that do not necessarily correspond to the inner user's feelings and are controlled directly by the sender. In this scenario, as part of our future work, we want to enrich the device with a privacy control (e.g. a led informing how public will be the message if sent), and explore the effect on senders and recipients.

People's attention is automatically drawn to novel things in our environment. We form schemas or expectations about what might happen next, given the context, and we prepare for such occurrence. We are surprised if this expectation is not met or uncertain if more than one expectation is aroused at once. Berylne [2] suggests this raises our arousal levels (readiness to react) and that slight transitory jumps in arousal can be pleasant because of the relief felt afterwards. This can be exploited in physical interfaces by coupling familiar physical objects with unexpected or unusual digital capabilities. By enabling direct control and feedback on a number of levels, providing aesthetic pleasure and supporting intrigue for the unexpected, physical user interfaces can help designers take the step beyond usability [8]. The design of our approach is relatively inexpensive due to it is based on the PhidgetInterfaceKit $8 / 8 / 8$, that cost $\$ 80$ CAD [19]. Much research has devoted to recognize subtle cues as evidence of emotion (e.g. gestures, actions, etc.) and to understand which particular emotion is being expressed. Our approach, however, aims to allow users to explicitly communicate a feeling (although it could be insincere), so they can engage in an emotional interchange and develop their own interpersonal emotional code. Related to collaborative scenarios, user control of their public emotions is very important, as they are constantly engaged in negotiation processes developing social strategies in order to accomplish a collective goal. Our approach would serve to build collaborative systems that tailor themselves according to users' public emotions. However much work need to be devoted to understand such approach and the ethics involved in these scenarios.

\section{CONCLUSIONS AND FURTHER WORK}

We have described a design of a physical emotional communication device. We have also outlined some preliminary observations regarding the usability of Emoti-Picture Frame as another possibility for interpersonal communication. We have explored affective communication based on Tangible User Interfaces that exploits the semantics associated to everyday objects such as a portrait, we have also introduced the concept What You See Is What I Feel, in this new kind of interpersonal communication.

We comment the advantages, initial inconveniences and findings from our first implementation and experience using the Emotive-Picture Frame. We plan to explore other modes of interaction and to study the use of this device by more users in order to expand our understanding of remote interpersonal communication based on emotions. Thus, we plan to improve Emoti-Picture Frame by incorporating more LCD displays, wireless connectivity, the possibility to send notes or audio, etc. Emotions representation (e.g. through colors) chosen may be outside the perception scope of disabled people, a new version of the prototype exploring more disruptive representation (e.g. through audio, or movements) can be explored as well, provided that we fully understand the interpersonal and emotional communication mechanism. This new features will enrich the space of affective communication using physical devices.

\section{REFERENCES}

[1] W. Ark and T. Selker. "A look at human interaction with pervasive computers". IBM systems Journal. Vol. $38 \mathrm{~N}^{\circ}$ 4. 1999.

[2] D.E. Berlyne. "Conflict, Arousal and Curiosity". McGraw-Hill. 1960.

[3] Ceiva. Sharing Made Easy. URLs: http://www. ceiva.com

[4] A. Chang, B. Koerner, X. Wang and H. Ishii. "LumiTouch: An Emotional Communication Device”. Ext. Abstracts CHI. ACM Press, pp. 313-314. 2001.

[5] B. Charlton. "Evolution and the cognitive neuroscience of awareness, consciousness and language". In Psychiatry and the human condition. Radcliffe Medical Press: Oxford, UK. 2000. 
[6] A.R. Damasio. "Descarte's Error: Emotion, Reason, and The Human Brain". New York, NY: Gosset/ Putnam Press. 1994.

[7] Emotional Intelligence Society. URLs: http://eqi. org/aware.htm

[8] R. Fleck. "Physical Interaction (PI03) -Workshop on Real World User Interfaces". Workshop at the Mobile HCI Conference 2003. Udine, Italy. September 8, 2003.

[9] Flyte and Nilsen. "Understanding attributes that contribute to pleasure in product use". W.S. Green and P.W. Jordan (Editors.). Pleasure with products: Beyond Unsability. Chapter 19. Taylor \& Francis. London. 2002.

[10] O. García, J. Favela, G. Sandoval and R. Machorro. "Extending a collaborative architecture to support emotional awareness. Auton. Agents". Seattle, Wa. Emotion Based Agent Architectures (ebaa'99), pp. 46-52. 1999.

[11] S. Greenberg and C. Fitchett. "Phidgets: Easy development of physical interfaces through physical widgets". Proceedings of the ACM UIST'01 Symposium on User Interface Software and Technology. Orlando, Florida. ACM Press. 2001.

[12] J. Heiner, S.E. Hudson and K. Tanaka. "The Information Percolator: Ambient Information Display in a Decorative Object”. Proc. UIST '99. ACM Press, pp. 141-148. 1999.

[13] H. Ishii and B. Ulmer. "Tangible bits: Towards seamless interfaces between people, bits and atoms". Proceedings of the ACM CHI'97, pp. 234-241. 1997.

[14] Y.Itoh, A. Miyajima and T. Watanabe. "TSUNAGARI' Communication: Fostering a Feeling of Connection between Family Members". Ext. Abstracts CHI'02, ACM Press, pp. 810-811. 2002.

[15] N. Khai, R. Heather, R. Gillian and D. Gregory. "Devices for Sharing Thoughts and Affection at a
Distance". Ext. Abstracts CHI’04, pp. 1203-1206. ACM Press. 2004.

[16] B.K. Laurel. "Interface as Mimesis". D.A. Norman and S.W. Draper (Editors). User-Centered system design: new perspectives on human-computer interaction. Erlbaum, Hillsdale, N.J. 1986.

[17] R. Lazarus, A. Kanner and S. Folkman. "Emotions: Theory, Research and Experience". Vol. 1. Academic Press. 1980.

[18] N. Mace. Editor. "Dementia care: Patient, family and community". Baltimore, MD: Johns Hopkins University Press. 1990.

[19] Phidgets Inc. - Developer and Manufactures of Phidgets. URLs: http://www.phidgets.com

[20] R.W. Picard. "Affective Computing". M.I.T. Press, Cambridge, MA. 1997.

[21] B. Scheiderman. "Designing the user interface: Strategies for effective human-computer interaction". $3^{\text {rd }}$ Ed. Addison-Wesley. Reading M.A. 1998.

[22] J. Scheirer and R. Picard. "Affective Objects". MIT Media lab Technical Rep. No 524. 2000.

[23] I. Siio, J. Rowan and E. Mynatt. "Peek-A-Drawer: Communication by Furniture". Ext. Abstracts CHI'02, ACM Press, pp. 582-583. 2002.

[24] E. Thompson. "Colour Vision: A Study in Cognitive Science and the Philosophy of Perception". London: Routledge Press. 1995.

[25] P. Valdez and A. Mehrabian. "Effects of color on emotions". Journal of Experimental Psychology: General, pp. 394-409. 1994.

[26] C. Wisneski, H. Ishii, A. Dahley, M. Gorbet, S. Brave, B. Ullmer and P. Yarin. "Ambient Displays: Turning Architectural Space into an Interface between People and Digital Information". Proc. CoBuild 1998, pp. 22-32. 1998. 